\title{
PLANNING FOR ACTION: TURNING MEANINGFUL DATA INTO PROGRAMS AND PROMOTION
}

\author{
Eleanor Howe \\ Librarian, Senior School Coordinator of Library Services K-12 \\ Shady Side Academy \\ 423 Fox Chapel Road \\ Pittsburgh, PA 15238 USA \\ Jack Stack \\ Library Media Specialist \\ Pine-Richard School District, Pennsylvania USA \\ Marcia Rettig-Seitam \\ Librarian/Television Coordinator \\ Freedom School District, Pennsylvania USA
}

\begin{abstract}
This workshop presents guidelines and tools for action research in the school library which will help the librarian justify expenditures and personnel and evaluate and plan services. It shows how statistics can be turned into meaningful knowledge about what is currently being done in your library, how well it is being done, whether it should be done, and what needs to be known to prepare for the future. Included are types of measurements, measurement techniques, meaningful data analysis, and pungent reporting of data to a variety of audiences.

All institutions, including libraries, need to assess their value and performance in order to justify funding. In an era of increased expenses and reduced funding, programs which are not highly rated can be deprived of even maintenance levels of funding, phased out, or placed on the ballot for referendum by taxpayers. Information technology has dramatically increased the budgets of school libraries, and school librarians need to demonstrate the real benefits of these technologies for students. It is also necessary to assess the total school library program, and action research is a tool which can help to examine, report on, and improve library operations. Assessing operations and ascertaining the worth of the library program are good mechanisms to justify steady funding.

The goal of action research is to improve management or solve problems at a single site by collecting data which reveals current practices in the researcher's own library (Isaac \& Michael, 1995). While it must be carefully done, action research is not theoretical, applied, or experimental research (McMillan, 1992). Action research involves gathering and analyzing data in our own library, and it may help us determine the degree to which we are meeting our missions and delivering services. Action research can therefore help confirm successes, acknowledge weaknesses, modify or remove unproductive activities, and plan for the future.

Action research utilizes measurement techniques, but there are limits to measurement. Not all projects or services lend themselves to easy measurement. Even when projects and services can be easily quantified, it may sometimes be difficult to ascertain what the quantities actually reveal. Two important considerations related to measurement and the interpretation of results are validity and reliability. Validity is the degree to which an instrument measures what it is intended to measure. It can also refer to the extent to which inferences from measurements are appropriate. Reliability is the degree to which measures are free from internal error and remain constant over time (McMillan, 1992).
\end{abstract}




\section{WHAT NEEDS TO BE MEASURED IN SCHOOL LIBRARIES ?}

Four questions illustrate what needs to be measured in school libraries in order to determine current practices, assess progress toward goals, make modifications, and justify new programs, technologies and staff:

What is the library currently doing?

How well is the library doing it?

Should the library be doing it?

What needs to be known about the future?

A variety of quantitative and qualitative measurement techniques can provide answers to these questions.

\section{WHAT CAN BE MEASURED IN SCHOOL LIBRARIES?}

School libraries are a natural place for action research since so many aspects of library service and programs can be counted. Public librarians calculate output and services based on library use measures, materials use measures, materials access measures, reference services, and programming (Van House, 1987). School librarians can use similar quantitative and qualitative assessment tools.

What can be measured in the school library includes things easy to count such as time, collection, facilities, people, money, and occurrences in programs and circulation. These simple quantitative measures can be used to indicate what the library is doing.

The following qualitative measures indicate how well services are delivered: accuracy, efficiency, accessibility, responsiveness, learning, and success/failure ratios for reference services and the collection. Other qualitative measures indicate how well the library is interacting with its service community and how it is perceived by that community: influence, impact, relevance, satisfaction, support, and the degree of consensus or discrepancy between the views of the library and its users.

After using action research to determine what is being done and how well, the results can be analyzed to make decisions to continue or modify allocations of staff, programs, and services. In order to plan for the future, school librarians should develop priorities and estimate the time, money, facilities, and services needed to achieve them.

\section{HOW TO MEASURE}

\section{Types of Data}

The goal of an action research project should determine the type of data to be collected, the methods of collection, and the measurement techniques. There are two basic types of data: quantitative and qualitative. Quantitative data are comprised of facts with objective reality and are expressed numerically. There is a reliance on numbers and counting, experiments, and statistics in quantitative research (McMillan, 1992). Quantitative data in school libraries can be collected with tally sheets, automated library software which calculates circulation and collection statistics, some types of observations, and some types of questions on questionnaires and interviews.

Qualitative data relies on the perceptions of the subjects. There is more emphasis on opinion, verbal descriptions, and naturally occurring situations in qualitative research (McMillan, 1992). Methods to collect qualitative data in school libraries include observations, discussions, interviews, and surveys. Questions call on the subject to use his or her perceptions and evaluations in making a response. Judgment or personal intervention on the part of the researcher may also affect the analysis of the data collected. For example, answers to open-ended questions on a questionnaire or an interview will require the data collector to group answers into categories or responses. The researcher can predetermine these categories based on his or her assumption of expected results or develop the categories while tabulating the answers given to the open-ended questions. In either case the data may be affected by the collector.

\section{Measurement Techniques}

The measurement technique selected flows from the type of data collected and the goals of the action research. Measurement techniques may be quantitative, qualitative, or a combination of both. 
Counting items is the technique most often used for collecting data. The question of validity is important to consider even for counting. For example, a turnstile can count people entering the library but it will also count employees returning from lunch and people needing a bathroom as well as a book. Circulation statistics cannot indicate whether an item was useful or enjoyed. A tally sheet should be developed using the categories to be measured and the measures should be as concise and as clear as possible. Examples of counted items in a school library are the number of walk-in students, the number of classes taught, the number of books in a collection, and the number of circulations.

The before/after measurement technique counts items in order to assess the impact of an intermediary intervention. Care must be taken that the measure selected will actually measure the effect of the treatment and that there are no other intervening variables which could explain the change. For example, in order to determine the impact of an event on circulation, count circulation before and after an event such as an author visit or the initiation of resource-based learning.

An inflation/deflation index is calculated on a constant unit of measurement such as a selection of books, periodicals, or AV materials. The percent of change in the cost of that unit is calculated by comparing the cost in a given year to the cost of that unit in the prior year or a base year. For example, the percentage increase in the average cost of a selection of books on standing order could be calculated between the current year and the prior year or when the standing order began.

Content analysis is a systematic, objective, and quantitative technique for evaluating the content of media through counting rather than evaluative analysis. Its goal is to eliminate bias and decrease subjectivity (Busha \& Harter, 1980). Documents are examined, items to be counted are identified and put into categories, and the number of occurrences are tallied. While most content analysis is performed on large numbers of media, such as types of sensational material in best selling novels or themes in young adult novels, the school librarian can use content analysis to determine if library resources are being used by students by counting the number of reference books cited in a group of class term papers.

Collection mapping involves counting items in various classification areas of the collection and making a visual representation of that data. This data can be used to evaluate the collection by comparing the number of items with the use of these areas of the collection by resource-based learning projects (Loertscher, 1996). A conspectus is a particular type of collection evaluation in which areas of the collection are assigned to each course in the curriculum and counted so that collection support for each course can be ascertained.

Relevance of materials is measured by users who rate each item according to a predetermined scale. This is a qualitative technique because judgment is used in placing an item into a category or degree of relevance.

Success/failure measures can count the number of times a particular event or item is considered a success or a failure. While this is counting, it is a qualitative technique because personal judgment determines whether an event is a success or a failure and also establishes what is an "acceptable" success/failure rate. An example is a study of user expectations in finding a specific title or whether a reference question has been successfully answered.

Best professional judgment is an inherently qualitative technique. Qualified persons are asked to make judgments about a situation by applying a specific rating scale to items they are evaluating. Other uses of best professional judgment are focus groups and consensus/discrepancy techniques. A focus group can brainstorm about problems and generate possible solutions. The group, which ideally consists of seven to twelve members, should have a set of questions or topics for discussion. A consensus/discrepancy analysis asks various disparate groups such as staff and users to rate aspects of library service. This permits the researcher to compare how each group perceives library services and to identify differences of opinion. For example, staff may believe that there are adequate electronic resources while users would like to have more workstations available.

Methods which can utilize both quantitative and qualitative data and techniques include questionnaires, interviews, observations, rubrics, and case studies. Questionnaires and interviews require careful wording and explanations of technical terms. One instrument can include a variety of quantitative and qualitative questions such as demographic data, occurrences, amount of time, success/failure, satisfaction, or relevance. The questions may be structured, with a selection of categories for response, or open-ended. It is advisable to pre-test the instrument on a sample group to 
identify questions which may be misleading or unclear. The instrument may be distributed to the entire population or to various types of samples. A student survey can provide information about student use of library resources, the level of student information skills, or student satisfaction with library services and programs.

The trained observation technique may also include both quantitative and qualitative data. The process of collecting the data is personal observation rather than instruments such as surveys. The bias of the observer in selecting, recording, and reporting observations is a potential problem which may be reduced through training and structured observations (Busha \& Harter, 1980). In the school library, a trained observer may be asked to count and evaluate staff, activities, student behavior, or items for their quality.

Rubrics transform expectations into degrees of success and become grading sheets for assessment. This type of measure has been used when it is very difficult to apply a numeric assessment, but the descriptions of each category must be well-defined and mutually exclusive in order to ensure accurate assessment.

Case studies are a means of examining the unique problems of groups or situations by using a variety of both quantitative and qualitative data-gathering methods such as observation, surveys, counting, and interviews. In this way comprehensive information about a particular topic is assembled. Its purpose is usually to discover and describe what exists or what occurs (Busha \& Harter, 1980). Case studies may be conducted on groups of library users such as students or faculty or a particular project such as a unit in resource-based learning. While a case study may identify problems to be addressed, it is less suitable for generalization because it is based on one possibly unique situation.

The selection of one or more of these research techniques should be suited to the goals of the research, the questions to be answered, or the problems to be solved.

\section{ANALYZING THE DATA}

The method selected to analyze the data depends upon the type of data collected-quantitative or qualitative. Methods of quantitative data analysis include measures of central tendency, ranking, collection mapping, inflation/deflation indexes, and content analysis. Some qualitative measurement techniques inherently involve analysis: success/failure analysis, relevance, before/after techniques, consensus/discrepancy measures, and case studies.

\section{Quantitative Analysis}

Measures of central tendency can be applied to counted items. They include the calculation of the mean, median, and mode. The mean is the easiest and quickest statistic to compute, for it is simply the arithmetic average. It is used to show the center of a sample, for example the average cost of a selection of books.

The median is the mid-point in a ranked list of scores, the point at which half the ranked scores are above and half are below. The median shows the upper and lower halves of the distribution but not distance from the central point. In the school library, the median can indicate the mid-point publication date of a selection of books or an area of the collection.

The mode is the most frequent score or response in a ranked list of scores. It is used to locate the most typical case, the item with the most occurrences. In the school library, the mode can be used to determine which grade level or form circulates the most materials. It can also be used in collection evaluation to determine which area of the collection has the most items.

Some qualitative techniques can be subject to quantitative analysis. The results of interviews and questionnaires, ranking and rating scales, success/failure analysis, and collection mapping can be logged onto a tally sheet. Open-ended responses can be collapsed into meaningful categories and each category counted. Data compiled on tally sheets from various quantitative and qualitative measures can provide answers to the questions of what we are doing and how well we are doing it.

\section{Qualitative Analysis}

Measures of central tendency and rank turn quantitative data into qualitative information by determining the relative importance of counted items. Other qualitative techniques such as case studies and consensus/discrepancy measures use various forms of qualitative analysis and judgment. 
The researcher's personal judgment is used to determine what categories to use, the degree of differences in measuring items, or how an item is viewed in the context of the user's application.

Compilation and analysis of data can be the most time consuming aspect of action research. Applying a variety of questions to the data and determining the answers without bias is easier to accomplish with quantitative than qualitative data.

\section{REPORTING THE DATA}

\section{Who Needs the Data?}

The first thing to be considered in reporting the results of action research is who needs the data and for what purpose. One goal of action research is to identify and evaluate library operations and progress toward missions, and the major beneficiary of such an analysis will be, the school librarian.

Action research can also be undertaken for a specific purpose or to justify changes in policies or funding. For instance, data can be collected to show the benefits of flexible scheduling, to demonstrate the need for additional clerical or professional staff, to request increased funding for materials to support changes in the curriculum or additional resource-based learning, and to justify the purchase of new technologies.

The results of action research should be reported to those within and beyond the school library who need the information for decision-making. They can also be given to other constituencies within the school setting such as such as department heads, supervisors, principals, school boards, parents, faculty, and volunteers. Seek opportunities to report on the school library to groups beyond the school with an interest in education, information, and books such as community, professional, service, and volunteer groups.

\section{What to Report?}

Action research is a means of gathering data to describe practices, facilitate decision-making, or to support proposals. The goal in reporting the data from action research is to select and organize it in such a way that it makes meaningful and memorable points about the school library.

One way to make quantitative and qualitative data more meaningful to administrators and the public is to use per capita data rather than numeric totals. The advantages of per capita data are that they take the user's point of view and that they enable more accurate comparisons and trend analysis. Per capita data can show the extent of school library service to each member of the community, and they can show the relative use of each type of service by the average member of the community. For example, you can determine what users are doing in the school library by comparing annual per capita circulation with annual per capita reference questions and annual per capita in-house use of materials.

Per capita data can also demonstrate to funding bodies and administrators the efficiency of investing in the library. It can show what is budgeted or spent per student for school library service and what the student receives in return. For example, compare the annual per capita cost of school library materials with the cost of purchasing at a store, the average per capita circulation over the year. For example, the cost of school library materials per student is calculated to be US $\$ 25$, the cost of one hardback book, and the average annual circulation per student is six books. The cost of purchasing six currently popular books in the collection may be about US $\$ 150$, but the cost to the student for taking out those same books at the school library is only US \$25. Also included in this US \$25 student per capita investment in school library materials is the student's in-house use of school library resources such as reference books, indexes, databases, and CD-ROMs. For the cost of one hard back book per year, the student gets access to the entire collection.

A second method of making quantitative and qualitative data about the school library meaningful is to make comparisons. Life-size comparisons are useful for administrators and the public. For instance, place the annual number of visits to the school library in school buses or the auditorium. How many school buses would be needed to bring all users to the school library each year? How many times does school library attendance fill the auditorium each year? The cost of school library materials can be expressed in terms of their comparative value in the consumer market place. This usually demonstrates the efficiency of investment in the library. In the same example, the student with an annual per capita cost of school library materials of US \$25 could spend the same 
amount of money over the whole year to purchase a nonrenewable resource such as five movie tickets or two large pizzas. The US \$25 investment in school library materials, however, enables the student to check out two books or two hundred books. In fact the more the student uses the library, the more cost effective it becomes and the more return the student receives on the annual per capita investment in materials.

One way to determine how well your school library is doing is to compare it with state, provincial, or national standards or with similar types of school libraries. Select the data for comparison such as budget, collection, or facilities. Identify relevant standards or peer schools for comparison. Peer schools should be similar in size of student body, location, grade or form level, and type of school. Such comparisons may be important to those who are responsible for the quality of education provided-administrators and boards of directors.

An important comparison to make for funding bodies is the rate of inflation of school library materials versus the cost of living index. The rate of inflation for school library materials such as magazines, books, and information technologies has often been greater than that for the general cost of living.

Reporting trends is a third way to make the results of action research meaningful. Per capita and comparative data can be collected over a period of years from quantitative and qualitative measures to indicate what the school library has done over that period of time. The results can be used to determine practices, assess progress, and make projections or changes. Expressing the trend data in per capita form is the most accurate form of comparison over time.

Trend analysis can also help evaluate the collection. Tracking the number or cost of actual purchases of the various types of materials in your school library over a five-year period enables you to see clearly which formats have been emphasized. Trend analysis can help also assess the relevance of the collection. To determine if you are purchasing what your students need, track over a five-year period the number of purchases in a particular classification area of the collection and compare that with the number of circulations in that same classification area.

\section{How to Report}

A written or oral report should be accompanied by a one-page summary of important points and by visuals which dramatically illustrate the points and make them easy to remember. Graphics should be limited to one issue per page and they should be more visual than numeric. Use simple line or bar graphs, pie charts, or illustrations. Line graphs can effectively illustrate inflation indexes and trend analysis. Bar graphs can dramatically demonstrate comparisons. Pie charts can graphically represent areas of the collection. Spread sheet programs can transfer the collected numeric data into graphics.

Written reports, summaries, and graphics can be combined into a publication which describes your school library. Most sports teams have marvelous "media books" that contain the vital statistics on coaches, players, the win and loss records for the team for the life of the team. Pictures, charts, and graphs decorate the pages so that the records are both attractive and informative. Before the advent of desktop publishing, such a venture would be costly in time and publishing. However, with modern technology, school librarians can create such a publication to help administrators, funding bodies, users, and the local community understand what the school library is all about. It seems imperative that school librarians publish a pamphlet or brochure to tell the story of their school library.

\section{CONCLUSION}

Time is a precious commodity for school librarians, but the time invested in an action research project may yield significant dividends in improved services and funded projects. Among all the possible action research projects, the school librarian should select those which provide the data to describe the library, solve a problem, or fulfill an important current need such as flexible scheduling, increased clerical or professional staff, or increased budget to support resource-based learning or additional technology. Design the action research project to provide answers to one or more of the original questions: what is currently being done in the library, how well is it being done, should it be done, and what is needed for the future. Present the problem and the research results to persons or bodies who need the data to make informed decisions, and make the school library known for the excellence of its collection, services, and management. 


\section{NOTES}

The authors wish to thank their colleagues in the Three Rivers Pittsburgh: Research Group for their encouragement to develop this paper from a larger project undertaken by the Group.

\section{REFERENCES}

Busha, C.H. \& Harter, S.P. (1980). Research methods in librarianship: Techniques and interpretation. San Diego, CA: Academic Press.

Isaac, S. \& Michael, W.B. (1995). Handbook in research and evaluation for education and the behavioral sciences (3rd ed.). San Diego, CA: EdITS.

Loertscher, D. (1996). Collection mapping in the LMC: Building access in a world of technology. Castle Rock, CO: HiWillow Research.

McMillan, J. H. (1992). Educational research: Fundamentals for the consumer. New York: Harper Collins.

Van House, N.A. [et al.]. (1987). Output measures for public libraries: A manual of standardized procedures (2nd ed.). Chicago: American Library Association. 